\title{
Efeito da Restrição Alimentar Qualitativa no Desempenho, na Incidência de Distúrbios Metabólicos e no Rendimento de Carcaça em Frangos de Corte
}

\author{
Helenice Mazzucoㄹ, Fátima Regina Jaenisch ${ }^{1}$, Antonio Lourenço Guidoni ${ }^{1}$
}

\begin{abstract}
RESUMO - Este estudo foi realizado para avaliar o desempenho, o controle da manifestação de doenças metabólicas e o rendimento de carcaça de frangos de corte machos submetidos à restrição alimentar no período de 8 a 14 dias de idade. A restrição nutritiva da dieta foi obtida diluindo-se a dieta inicial (21,5\% PB e $3050 \mathrm{kcal} / \mathrm{kg}$ EM) com 25 e $50 \%$ de casca de soja. Os tratamentos de restrição envolveram a oferta dessas dietas de forma contínua ou intercalada (com a dieta inicial não-diluída). Após o período de restrição, as aves retornaram ao consumo da ração inicial até os 21 dias de idade. No período seguinte, 22 a 35 dias de idade, as aves receberam ração de crescimento (21\% PB e 3200 kcal/kg EM) e de 36 a 42 dias, ração final (19\% PB e 3200 kcal/kg de EM). Após terem sido submetidas à restrição alimentar, as aves mostraram pesos corporais inferiores aos das aves do tratamento controle em todas as idades avaliadas. A diluição da dieta não influenciou a manifestação da síndrome ascítica ou morte súbita. Não houve diferença no rendimento de carcaça, peito e coxas. O conteúdo em gordura abdominal não mostrou diferenças consistentes entre tratamentos. Os tratamentos em que se utilizou a diluição com 50\% de casca de soja apresentaram menor margem bruta. A estratégia nutricional, para reduzir as perdas por mortalidades de origem metabólica e o teor de gordura abdominal na carcaça foi acompanhada por perdas em termos de desempenho das aves.
\end{abstract}

Palavras-chave: composição da carcaça, desempenho, dieta, diluição, frangos de corte, restrição, síndrome ascítica, síndrome da morte súbita

\section{Qualitative Feed Restriction Effects on Growth Performance, Metabolic Disorders and Carcass Traits of Broiler Chickens}

\begin{abstract}
This experiment was conducted to evaluate the performance, control of the of metabolic diseases incidence, and carcass yield of male broiler chickens allotted to a feed restriction from 8-14 days of age. The nutrient restriction was achieved by feeding a starter diet $(21,5 \% \mathrm{CP}$ and $3050 \mathrm{ME}, \mathrm{kcal} / \mathrm{kg})$ with 25 or $50 \%$ soybean hulls. The treatment of restriction involved the feeding of these diets either on continuously or intercalated form (with the non-diluted starter diet). After the restriction period, the birds returned to the regular starter diet up to 21 days of age. In the following period, from 22 to 35 days of age, the birds were fed a growing diet ( $21 \%$ $\mathrm{CP}-3200 \mathrm{ME}, \mathrm{kcal} / \mathrm{kg}$ ) and from 36 to 42 days, a finishing diet (19\% CP - $3200 \mathrm{ME}, \mathrm{kcal} / \mathrm{kg}$ ). After they have been submitted to the feed restriction, the birds showed lower body weights as compared to the control treatment for all ages. The diet dilution did not influence the incidence of ascites or sudden death syndromes. There were no differences on carcass breast or thigh yield. Abdominal fat content presented no consistent differences among treatment. The treatments with diet dilution of $50 \%$ of soybean hulls resulted on inferior gross margin. The nutritional strategy to reduce the losses by metabolic diseases and the abdominal carcass fat content was accomplished by losses on the performance of the birds.
\end{abstract}

Key Words: carcass composition, performance, diet, dilution, broilers, nutrient, restriction, ascites syndrome, sudden death syndrome

\section{Introdução}

A maior parte das pesquisas referentes à restrição alimentar foi conduzida para se reduzir o crescimento inicial das aves, para posterior recuperação do peso final, visando, principalmente, ao incremento da produção de carcaças com reduzido conteúdo em gordura. Os estudos de GRIFFITHS et al. (1977), PLAVNIK e HURWITZ (1985) e ZUBAIR e LEESON (1994) são clássicos nesse sentido. Com o aumento na demanda de produtos avícolas pós-processados, existe interesse considerável na composi- ção e qualidade da carcaça de frangos de corte. Como a presença de gordura na carcaça pode ser alterada por intermédio da manipulação dos níveis energéticos da dieta, há possibilidade de redução na deposição dessa gordura corporal, limitando-se à ingestão de energia pelas aves (LEESON et al. 1996).

Na tentativa de reduzir a manifestação da síndrome ascítica em frangos de corte, diferentes formas de aplicação de programas de restrição alimentar também foram abordadas em estudos como os de ARCE et al. (1992), ROBINSON et al. (1992) e ACAR et al. (1995). Com a restrição alimentar, há redução do

${ }^{1}$ Pesquisador da Embrapa Suínos e Aves - BR 153 km 110, Vila Tamanduá, Caixa Postal 21 Concórdia, SC - Brasil. 
peso corporal e conseqüente diminuição na atividade metabólica e demanda por $\mathrm{O}_{2}$, o que limita a predisposição das aves à hipoxia, que origina a hipertensão pulmonar -característica em aves que apresentam o quadro da síndrome ascítica. ARCE et al. (1992) concluíram que a restrição alimentar foi um instrumento eficaz no controle da Síndrome Ascítica (SA) em frangos de corte, porém, autores como SHLOSBERG et al. (1991) e ROBINSON et al. (1992) não obtiveram resultados satisfatórios no controle da SA, ao aplicarem os programas de restrição alimentar. LEESON e SUMMERS (1988) afirmaram que menor velocidade de crescimento durante determinado período pode ser importante para se alcançar o desenvolvimento normal das aves, prevenindo-se problemas de pernas e reduzindo o número de aves refugos. Segundo YU et al. (1990), a restrição alimentar, aplicada em idade precoce e a posterior realimentação alteram a curva de crescimento, resultando em economia de ração e redução na deposição de gordura abdominal na carcaça. No entanto, o fenômeno da compensação do peso em frangos de corte, segundo PALO et al. (1995), é complexo e multifatorial, uma vez que interagem aspectos fisiológicos, nutricionais, metabólicos e endócrinos. O presente experimento foi delineado com o objetivo de estudar as respostas de frangos machos submetidos à restrição alimentar, entre o $8^{\circ}$ e e $14^{\circ} \mathrm{O}$ dia de criação, imposta por intermédio da diluição da dieta (redução do nível energético e protéico) no controle da incidência da síndrome ascítica e morte súbita, rendimento da carcaça e cortes, desempenho e resultado bioeconômico. A influência do fornecimento das dietas diluídas em períodos alternados ou contínuos também foi avaliada no presente estudo.

\section{Material e Métodos}

Três mil e quinhentos pintos machos de um dia, de uma linhagem comercial, foram equalizados por peso inicial e distribuídos em 25 boxes $\left(11,38 \mathrm{~m}^{2}\right)$ com 140 aves/box e criados até o 7 o dia de idade sob uma dieta inicial (conforme Tabela 1), formulada de acordo com as exigências da linhagem e recebendo a mesma composição nutritiva. Optou-se pela utilização de machos, por serem mais suscetíveis à manifestação de distúrbios metabólicos, bem como pelo período de inverno, para a condução do estudo. As temperaturas foram monitoradas em dois horários, 8 e 16 h, obtendo-se respectivos valores de $18 ; 23,5 ; 12,5 ; 32$; e $5^{\circ} \mathrm{C}$ para temperaturas médias, médias das mínimas, mé- dias das máximas, máximas e mínimas absolutas.

Cada tratamento foi representado por cinco repetições totalizando 700 aves por tratamento e, no período de 8 a 14 dias, foram aplicados os tratamentos experimentais descritos a seguir: $\mathrm{T} 1$ = ração inicial (controle); T2 e T3 = ração inicial diluída com 25 e $50 \%$ de casca de soja, respectivamente, fornecida de 8 a 14 dias; e T4 e T5 = ração inicial diluída com 25 e $50 \%$ de casca de soja respectivamente, fornecida nos dias $8,10,12$ e 14, intercalada com a ração controle nos dias 9,11 e 13. Após o 14 o dia, todas as aves receberam a dieta inicial regularmente; dos 22 aos 35 dias de idade, consumiram a ração de crescimento (21\% PB e $3200 \mathrm{kcal} / \mathrm{kg} \mathrm{EM}$ ); e dos 36 dias até o abate (42 dias), receberam a ração final (19\% PB e $3200 \mathrm{kcal} / \mathrm{kg} \mathrm{EM}$ ). Aos 42 dias de idade, foram selecionadas seis aves pelo peso corporal médio do box, oriundas de cada repetição para o abate e cortes. As aves foram abatidas por sangria, depenadas, evisceradas e as carcaças submetidas aos cortes para posterior mensuração dos pesos. A gordura abdominal também foi extraída e pesada. O consumo e o peso das aves foram obtidos em intervalos de sete dias, até os 42 dias.

As mortalidades avaliadas diariamente foram classificadas da seguinte forma: Síndrome Ascítica (SA), quando detectado líquido abdominal de cor clara em qualquer volume; Síndrome da Morte Súbita (SMS), quando, a campo, a ave se apresentava em decúbito dorsal, peso médio igual ou superior à média do lote, com inglúvio repleto de ração e à necropsia, conforme GONZALES et al. (1994), trato gastrintestinal com alimento, coração dilatado ou contraído, aurículas cheias de sangue, vesícula biliar pequena ou vazia, pulmão congesto ou normal e ausência de lesões por outras causas; aves Refugos, eliminadas por apresentarem algum defeito físico e/ou peso corporal muito abaixo da média do box; e mortalidade por Outras Causas (OC), quando não classificadas nos itens anteriores.

No cálculo da margem bruta e obtenção do resultado bioeconômico, consideraram-se o preço da ave viva/kg na idade de 42 dias, o consumo e o preço das rações nas diferentes fases e o número de aves alojadas no primeiro dia, conforme a fórmula: Margem bruta $=[$ preço do frango em reais (kg/ave viva) $\mathrm{x}$ peso médio do frango aos 42 dias - (consumo da ração x preço da ração nas diferentes fases) - preço do pinto de um dia].

O delineamento estatístico adotado foi em blocos casualizados, com cinco repetições e cinco tratamen- 
Rev. bras. zootec.

Tabela 1- Composição das dietas experimentais

Table 1 - Composition of the experimental diets

\begin{tabular}{|c|c|c|c|c|c|}
\hline \multirow[t]{2}{*}{$\begin{array}{l}\text { Ingrediente } \\
\text { Ingredient }\end{array}$} & \multicolumn{5}{|c|}{$\begin{array}{c}\text { Dieta } \\
\text { Diet }\end{array}$} \\
\hline & $\begin{array}{l}\text { Inicial } \\
\text { controle } \\
\text { Starter } \\
\text { control diet }\end{array}$ & $\begin{array}{c}\text { Inicial } \\
\text { Diluída com } \\
25 \% \text { de casca } \\
\text { de soja } \\
\text { Starter diet } \\
\text { diluted with } \\
25 \% \text { of } \\
\text { soybean hulls }\end{array}$ & $\begin{array}{c}\text { Inicial } \\
\text { Diluída com } \\
50 \% \text { de casca } \\
\text { de soja } \\
\text { Starter diet } \\
\text { diluted with } \\
50 \% \text { of } \\
\text { soybean hulls }\end{array}$ & $\begin{array}{l}\text { Dieta crescimento } \\
\text { Growing diet }\end{array}$ & $\begin{array}{l}\text { Dieta final } \\
\text { Finishing diet }\end{array}$ \\
\hline $\begin{array}{l}\text { Milho } \\
\text { Corn }\end{array}$ & 56,38 & 41,21 & 27,48 & 55,07 & 61,92 \\
\hline $\begin{array}{l}\text { Farelo de soja }(48 \%) \\
\text { Soybean meal }\end{array}$ & 36,40 & 28,26 & 18,84 & 35,56 & 30,20 \\
\hline $\begin{array}{l}\text { Óleo de soja } \\
\text { Soybean oil }\end{array}$ & 3,11 & 2,50 & 1,66 & 5,78 & 4,52 \\
\hline $\begin{array}{l}\text { Fosfato bicálcico } \\
\text { Dicalcium phosphate }\end{array}$ & 1,79 & 1,89 & 2,00 & 1,69 & 1,61 \\
\hline $\begin{array}{l}\text { Calcário } \\
\text { Limestone }\end{array}$ & 1,27 & 1,00 & 0,73 & 0,94 & 0,88 \\
\hline $\begin{array}{l}\text { Sal } \\
\text { Salt }\end{array}$ & 0,39 & 0,39 & 0,39 & 0,41 & 0,41 \\
\hline $\begin{array}{l}\text { Premix vitamínico } \\
\text { Vitamin premix }\end{array}$ & 0,10 & 0,10 & 0,10 & 0,1 & 0,1 \\
\hline $\begin{array}{l}\text { Premix mineral }^{2} \\
\text { Mineral premix }\end{array}$ & 0,10 & 0,10 & 0,10 & 0,1 & 0,1 \\
\hline $\begin{array}{l}\text { Cloreto de colina }(60 \%) \\
\text { Choline cloride }\end{array}$ & 0,10 & 0,10 & 0,10 & 0,1 & 0,1 \\
\hline $\begin{array}{l}\text { Coccidiostático } \\
\text { Coccidiostat }\end{array}$ & 0,06 & 0,06 & 0,06 & 0,06 & - \\
\hline $\begin{array}{l}\text { DL-metionina } \\
\text { DL-methionine }\end{array}$ & 0,24 & 0,17 & 0,12 & 0,17 & 0,16 \\
\hline $\begin{array}{l}\text { L-lisina } \\
\text { L-lysine }\end{array}$ & 0,04 & .- &.- & - & - \\
\hline $\begin{array}{l}\text { Antibiótico } \\
\text { Antibiotic }\end{array}$ & 0,01 & 0,01 & 0,01 & 0,01 & - \\
\hline $\begin{array}{l}\text { Cascas de soja } \\
\text { Soybean hulls } \\
\text { BHT }^{5}\end{array}$ & 0,01 & $\begin{array}{r}24,20 \\
0,01\end{array}$ & $\begin{array}{r}48,40 \\
0,01\end{array}$ & $\begin{array}{c}- \\
0,01\end{array}$ & $\begin{array}{c}- \\
0,01\end{array}$ \\
\hline $\begin{array}{l}\text { Conteúdo nutritivo } \\
\text { Nutrient content }\end{array}$ & & & & & \\
\hline $\begin{array}{l}\text { Proteína bruta }(\%) \\
\text { Crude protein }\end{array}$ & 21,5 & 18,7 & 15,5 & 21 & 19 \\
\hline $\begin{array}{l}\mathrm{EM}(\mathrm{kcal} / \mathrm{kg}) \\
M E\end{array}$ & 3050 & 2463 & 1875 & 3200 & 3200 \\
\hline $\begin{array}{l}\mathrm{Ca}(\%) \\
\mathrm{P} \text { disponível }(\%) \\
\text { Avaliable P }\end{array}$ & $\begin{array}{l}0,99 \\
0,44\end{array}$ & $\begin{array}{l}0,99 \\
0,44\end{array}$ & $\begin{array}{l}0,99 \\
0,44\end{array}$ & $\begin{array}{l}0,85 \\
0,42\end{array}$ & $\begin{array}{l}0,80 \\
0,40\end{array}$ \\
\hline $\begin{array}{l}\text { DL-metionina }(\%) \\
\text { DL-methionine }\end{array}$ & 0,54 & 0,43 & 0,33 & 0,46 & 0,43 \\
\hline $\begin{array}{l}\text { Metionina }+ \text { cistina }(\%) \\
\text { Methionine }+ \text { Cystine }\end{array}$ & 0,92 & 0,78 & 0,64 & 0,83 & 0,77 \\
\hline $\begin{array}{l}\text { Lisina }(\%) \\
\text { Lysine }\end{array}$ & 1,19 & 1,07 & 0,95 & 1,14 & 1,00 \\
\hline $\begin{array}{l}\text { kg da dieta: vit. A, } 10.000 .0 \\
\left.\text { (riboflavin) ( } \mathrm{B}_{2}\right), 6.000 \mathrm{mg} \text {; } \mathrm{n} \\
\text { mg; ácido fólico (folic acid), } \\
2 \text { Suplementou-se por kg da } \\
50.000 \text { mg; sulfato de ferro } \\
\text { (calcium iodate) (62\%) } 500 \\
3 \text { Coban 200 (ionóforo), EL } \\
4 \text { Tylan 40, ELANCO. } \\
5 \text { Butil-Hidroxi-Tolueno (antic }\end{array}$ & $\begin{array}{l}00 \mathrm{UI}^{\text {; vit }} \mathrm{D}_{3}, 2 . \\
\text { iacina (niacin), } \\
1.000 \mathrm{mg} ; \text { bic } \\
\text { a dieta: sulfato } \\
\text { o (iron sulfate) ( } \\
\text { mg; selenito d } \\
\text { ANCO. } \\
\text { ioxidante). }\end{array}$ & $\begin{array}{l}0.000 U l ; \text { vit E } 3500 \\
000 \text { mg; ácido pant } \\
\text { na (biotin), } 100 \mathrm{mg} ; \\
\text { manganês (magar } \\
\% \text { ) } 60.000 \mathrm{mg} \text {; sulf } \\
\text { sódio (sodium selen }\end{array}$ & $\begin{array}{l}\text { g; vit. K, } 3.000 \mathrm{mg} ; \\
\text { ênico (pantothenic aci } \\
\text { ita } \mathrm{B}_{12}, 20.000 \mathrm{mc} \\
\text { ese sulfate) (31\%) } 70 \\
\text { to de cobre (cupper } \\
(45 \%) 250 \mathrm{mg} \text {. }\end{array}$ & $\begin{array}{l}\text { iamina (thiamin) }\left(\mathrm{B}_{1}\right), 220 \\
\text { d), } 12.000 \mathrm{mg} \text {; piridoxina } \\
\text { g. } \\
.000 \mathrm{mg} \text {; óxido de zinco } \\
\text { sulfate) }(25 \%) 8.000 \mathrm{mg} \text {; }\end{array}$ & $\begin{array}{l}\text { my; riboflavina } \\
\text { pyridoxine), } 4.000 \\
\text { (zinc oxid) (31\%) } \\
\text { iodato de cálcio }\end{array}$ \\
\hline
\end{tabular}


tos. As análises foram realizadas pelo programa SAS, sendo as médias dos tratamentos comparadas pelo teste t a $5 \%$ de probabilidade, por intermédio do teste F. A mortalidade foi avaliada de acordo com PIMENTEL GOMES (1987).

\section{Resultados e Discussão}

\section{Peso corporal}

Segundo ENSMINGER (1992), as exigências energéticas diárias das aves durante a $2^{\mathrm{a}}$ semana de idade é 118,57 kcal de EM. Considerando os tratamentos mais severos do presente estudo (3 e 5), as aves foram submetidas à restrição energética, nesta idade, em 73 e 103 kcal EM/ave•dia, respectivamente. Foram observados baixos pesos corporais $(p<0,05)$ nas aves submetidas aos tratamentos de restrição a partir dos 14 dias de idade. A limitação da ingestão da energia da dieta aquém das exigências de mantença mostrou-se deletéria à recuperação do peso corporal, uma vez que as aves não atingiram o peso vivo das aves controle aos 42 dias de idade (Tabela 2). Mesmo após a realimentação, as aves não exibiram taxas de crescimento que viessem a compensar a perda do peso corporal durante o período da restrição. O peso corporal aos 42 dias das aves dos tratamentos 2 e 4 , embora não tenham diferido significativamente do peso das aves que receberam a dieta controle, apresentaram baixos valores para essa variável. Resultados semelhantes foram obtidos por ARCE et al. (1992), quando mostraram que a restrição alimentar ( 8 horas de acesso ao alimento ou 10\% de redução do consumo a vontade) reduziram o peso corporal das aves significativamente aos 53 dias de idade. Do mesmo modo, ROBINSON et al. (1992) concluíram que a dieta de restrição imposta às aves durante sete dias acarretou pesos corporais menores que os das aves controle. Ao aplicar a restrição qualitativa da dieta (50\% dieta inicial:50\% cascas de aveia moída) durante a segunda semana, ROBINSON et al. (1992) observaram pesos inferiores das aves em relação aos das aves submetidas à restrição quantitativa.

Conforme FONTANA et al. (1992), as médias de peso foram significativamente menores para as aves que receberam os tratamentos de restrição (40 kcal/ ave $\bullet$ dia) aplicados durante 5 dias, a partir do $4 \stackrel{0}{ }$ dia de idade. Os autores discutem que os pesos corporais foram baixos a partir do $14^{\circ}$ dia de idade, não havendo recuperação na idade de 42 dias. Quando se aplicaram análises de regressão, estimou-se que as aves necessitariam de aproximadamente 2 dias adicionais

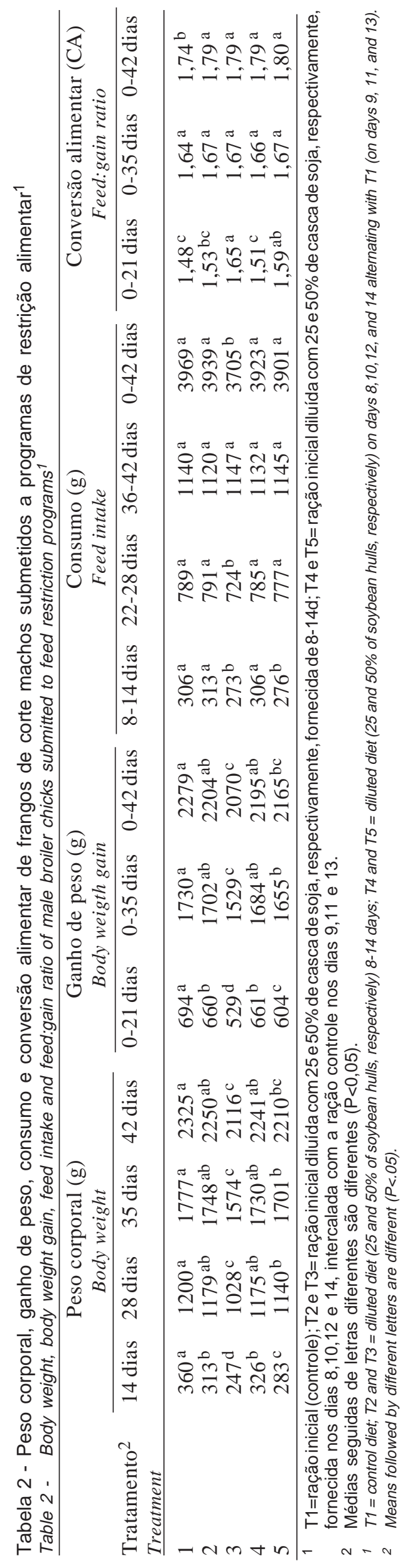


Rev. bras. zootec.

para atingir peso corporal comparável ao das aves controle aos 42 dias, ou seja, deveriam ser criadas até 44 dias de idade. Com base nas taxas de ganho de peso, ROBINSON et al. (1992) também argumentaram que as aves sob restrição necessitariam de 2 a 3 dias adicionais para atingir o peso das aves do tratamento controle.

Autores como ACAR et al. (1995) obtiveram pesos corporais abaixo do peso demonstrado pelas aves do tratamento controle aos 28, 35, 42 e 49 dias, ao aplicarem restrição alimentar com base na limitação da ingestão diária em $75 \%$ da EM exigida para o crescimento durante sete dias. Variando-se o período da restrição (sete dias contínuos ou intercalados com a dieta inicial), não houve recuperação do peso final. Isso concorda com as observações de ZUBAIR e LEESON (1994), quando aplicaram a restrição qualitativa da dieta (diluída com $50 \%$ de cascas de aveia) de forma intercalada ou contínua, o que, segundo os autores, pressupõe que o modo de distribuição da ração diluída em períodos intercalados não tem efeito sobre o crescimento compensatório.

Ganho de peso (GP)

No período total ( 0 a 42 dias, Tabela 2), as médias para o GP do tratamento controle não foram alcançadas pelas aves dos tratamentos em que se aplicou a restrição alimentar utilizando dietas diluídas com $50 \%$ de casca de soja. Embora apresentando taxas de crescimento compatíveis com os ganhos das aves do tratamento controle, após os 28 dias, os frangos não alcançaram o peso corporal aos 42 dias de idade. Resultado semelhante ficou caracterizado no estudo de FONTANA et al. (1992), mostrando que, embora as taxas de ganho de peso entre os tratamentos não fossem diferentes, as aves sob restrição não superaram o atraso no crescimento causado pela restrição alimentar. ZUBAIR e LEESON (1994) empregaram a restrição alimentar diluindo-se a dieta inicial com $50 \%$ de cascas de aveia e, durante o período de 42 a 49 dias, as aves submetidas à restrição ganharam significativamente mais peso que as aves controle. Sugere-se que as aves, no presente estudo, necessitariam de maior período de recuperação ou retorno à alimentação normal para a manifestação do ganho compensatório.

\section{Consumo}

As aves submetidas à restrição, no período de 8 a 14 dias, dos tratamentos 3 e 5 não aumentaram o consumo da ração de forma a compensar a menor ingestão energética (Tabela 2), resultado este distinto dos estudos de GRIFFITHS et al. (1977) e ZUBAIR e LEESON (1994).

O limite físico de consumo das aves pode ser causa provável para esse comportamento, associado ao maior volume de ração obtido com a diluição .

O oferecimento da ração diluída em períodos

Tabela 3 - Influência dos programas de restrição alimentar sobre a incidência de síndrome ascítica (SA), síndrome da morte súbita (SMS), outras causas (OC) e refugos em frangos de corte machos submetidos à restrição alimentar ${ }^{1}$ no período de 8 a 14 dias de idade

Table 3 - Influence of feed restriction programs ${ }^{1}$ on incidence of ascites syndrome, sudden death syndrome, other causes and culled birds in male broiler chicks submitted to feed restriction from 8 to 14 days of age

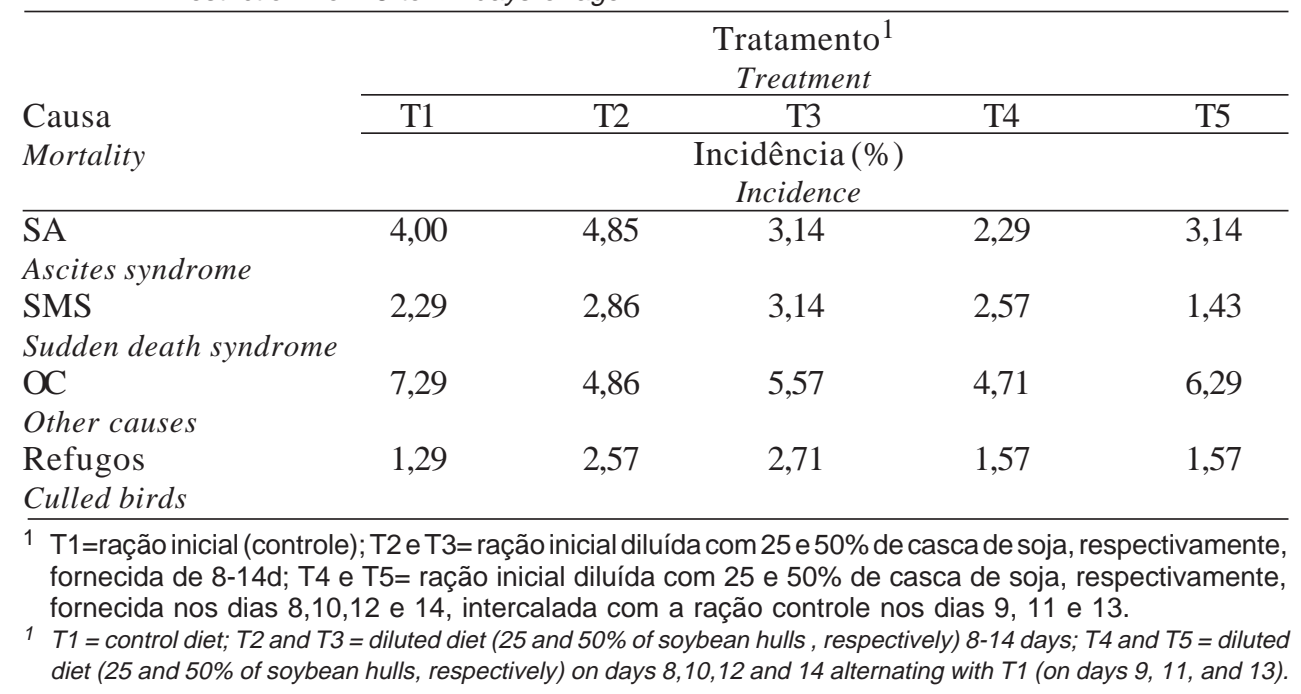


alternados (Tratamentos 4 e 5, Tabela 2) não mostrou efeito significativo no consumo durante o período total, o mesmo ocorrendo com o tratamento 2. ROBINSON et al. (1992) observaram que as aves submetidas à restrição quantitativa e qualitativa de forma contínua consumiram menos ração que as aves com consumo ad libitum e as que receberam a ração diluída de forma intercalada apresentaram consumo ainda menor.

\section{Conversão alimentar (CA)}

No período de 0 a 35 dias, não houve diferença entre os tratamentos; já no período de 0 a 42 dias esta diferença foi significativa $(\mathrm{p}<0,05)$ para os tratamentos em que se aplicou a restrição (Tabela 2). Ao aplicar a restrição qualitativa da dieta $(50 \%$ de cascas de aveia moídas), ROBINSON et al. (1992) também não obtiveram diferenças na $\mathrm{CA}$ aos 42 dias, ao compararem a restrição quantitativa ( 27 g/ave•dia) durante a segunda semana. ARCE et al. (1992) concluíram que a restrição aplicada com o objetivo de reduzir a incidência de SA acarretou em diminuição significativa do peso corporal e da conversão alimentar ao final do período de criação.

\section{Mortalidade}

Nenhum dos tratamentos de restrição alterou a incidência da mortalidade por SA ou SMS $(\mathrm{P}>0,05)$ (Tabela 3). O efeito dos tratamentos de restrição nas mortalidades por AS e SMS não pôde ser mensurado, em função da baixa incidência destas no lote.

ROBINSON et al. (1992), utilizando restrição qualitativa e quantitativa da dieta, também concluíram que os tratamentos aplicados não resultaram em diminuição significativa da mortalidade por SA e SMS. No entanto, os regimes de restrição alimentar aplicados por ACAR et al. (1995) reduziram significativamente a mortalidade por SA $(\mathrm{P}>0,05)$, quando empregaram a limitação diária do consumo a $75 \%$ da EM, exigida para o crescimento normal. ARCE et al. (1992) também aplicaram diferentes restrições alimentares ( 8 horas de acesso ao alimento ou $10 \%$ a

Tabela 4 - Efeito de programas de restrição alimentar ${ }^{1}$ sobre o rendimento de alguns cortes de carcaça

Table 4 - Influence of feed restriction programs ${ }^{1}$ on carcass characteristics of male broiler chicks

\begin{tabular}{|c|c|c|c|c|c|}
\hline \multirow{2}{*}{$\begin{array}{l}\text { Peso e rendimento } \\
\text { da carcaça }(\%) \\
\text { Carcass weight and yield }\end{array}$} & \multicolumn{5}{|c|}{$\begin{array}{c}\text { Tratamento }^{2} \\
\text { Treatment }\end{array}$} \\
\hline & 1 & 2 & 3 & 4 & 5 \\
\hline Peso da ave (g) & $2393^{\mathrm{a}}$ & $2316^{\mathrm{a}}$ & $2181^{b}$ & $2297^{\mathrm{ab}}$ & 2292 \\
\hline $\begin{array}{l}\text { Body weight } \\
\text { Peso da carcaça }(\mathrm{g})\end{array}$ & $1667^{\mathrm{a}}$ & $1586^{\mathrm{ab}}$ & $1501^{b}$ & $1595^{a b}$ & $1591^{\mathrm{ab}}$ \\
\hline $\begin{array}{l}\text { Carcass weight } \\
\text { Rendimento da carcaça }(\%) \\
\text { Carcass yield }\end{array}$ & $69,67^{\mathrm{a}}$ & $68,47^{\mathrm{a}}$ & $68,83^{\mathrm{a}}$ & $69,46^{\mathrm{a}}$ & $69,39^{\mathrm{a}}$ \\
\hline $\begin{array}{l}\text { Peso peito }(\mathrm{g}) \\
\text { Breast weight }\end{array}$ & $494,04^{\mathrm{a}}$ & $462,08^{\mathrm{ab}}$ & $434,48^{\mathrm{b}}$ & $460,60^{\mathrm{ab}}$ & $463,02^{\mathrm{ab}}$ \\
\hline $\begin{array}{l}\text { Rend. peito }(\%) \\
\text { Breast yield }\end{array}$ & $29,61^{\mathrm{a}}$ & $29,18^{a}$ & $28,91^{\mathrm{a}}$ & $28,87^{\mathrm{a}}$ & $29,10^{\mathrm{a}}$ \\
\hline $\begin{array}{l}\text { Peso coxas (g) } \\
\text { Thigh weight }\end{array}$ & $230,16^{a}$ & $225,90^{\mathrm{a}}$ & $209,69^{b}$ & $222,27^{\mathrm{ab}}$ & $220,20^{\mathrm{ab}}$ \\
\hline $\begin{array}{l}\text { Rend. coxas }(\%) \\
\text { Thigh yield }\end{array}$ & $13,80^{\mathrm{a}}$ & $14,29^{\mathrm{a}}$ & $13,97^{\mathrm{a}}$ & $13,94^{\mathrm{a}}$ & $13,84^{\mathrm{a}}$ \\
\hline $\begin{array}{l}\text { Peso sobrecoxas }(\mathrm{g}) \\
\text { Drumstick weight }\end{array}$ & $286,92^{\mathrm{a}}$ & $287,75^{\mathrm{a}}$ & $267,24^{\mathrm{a}}$ & $286,83^{\mathrm{a}}$ & $284,30^{\mathrm{a}}$ \\
\hline $\begin{array}{l}\text { Rend. sobrecoxas }(\%) \\
\text { Drumstick yield }\end{array}$ & $17,22^{b}$ & $18,17^{\mathrm{a}}$ & $17,80^{\mathrm{ab}}$ & $17,98^{a b}$ & $17,87^{\mathrm{ab}}$ \\
\hline $\begin{array}{l}\text { Peso gordura abdominal (g) } \\
\text { Abdominal fat weight }\end{array}$ & $39,37^{\mathrm{ab}}$ & $38,76^{\mathrm{ab}}$ & $35,88^{\mathrm{b}}$ & $37,49^{b}$ & $42,49^{\mathrm{a}}$ \\
\hline $\begin{array}{l}\text { Gordura abdominal }(\%) \\
\text { Abdominal fat yield }\end{array}$ & $2,36^{\mathrm{b}}$ & $2,45^{\mathrm{ab}}$ & $2,39^{\mathrm{b}}$ & $2,35^{\mathrm{b}}$ & $2,68^{a}$ \\
\hline $\begin{array}{ll}1 & \text { T1=ração inicial (controle); T2 } \\
\text { fornecida de 8-14d; T4 e T5 = ra } \\
\text { nos dias 8,10,12 e 14, intercala } \\
2 \text { Médias seguidas de letras dife } \\
1 \text { T1= control diet; T2 and T3 = diluted } \\
50 \% \text { of soybean hulls, respectively) } \\
2 \text { Means followed by different letters }\end{array}$ & $\begin{array}{l}=\text { ração inici } \\
\text { inicial diluída } \\
\text { om a ração c } \\
\text { S são diferen } \\
25 \text { and } 50 \% \text { of } \\
\text { ys } 8,10,12 \text {, an } \\
\text { ferent }(P<.05) \text {. }\end{array}$ & $\begin{array}{l}\text { diluída com } \\
\text { om } 25 \text { e } 50 \% \\
\text { ntrole nos dia } \\
\text { ( }(P<0,05) \text {. } \\
\text { ybean hulls, re } \\
14 \text { alternating }\end{array}$ & $\begin{array}{l}50 \% \text { de } \\
\text { casca de } \\
11 \text { e } 13 . \\
\text { ively) } 8-14 \\
11 \text { (on days }\end{array}$ & $\begin{array}{l}\text { soja resp } \\
\text { oectivamer } \\
\text { d } 13 \text { ). }\end{array}$ & $\begin{array}{l}\text { ivamente, } \\
\text { fornecida } \\
\text { diet (25 and }\end{array}$ \\
\hline
\end{tabular}


menos do consumo a vontade) e obtiveram redução da incidência de SA.

\section{Rendimento de carcaça e cortes}

Para o rendimento de carcaça, não houve diferenças entre tratamentos (Tabela 4 ). O rendimento do peito em relação ao peso da carcaça também não diferiu entre tratamentos, o mesmo ocorrendo com relação ao peso e rendimento de sobrecoxas (Tabela 4). As diferentes formas de aplicação dos programas de restrição não resultaram em redução da gordura abdominal da carcaça. Para essa variável não houve diferenças de resposta entre as aves do tratamento controle e as aves sob restrição contínua ou alternada. Diferença significativa foi mostrada apenas entre as aves sob restrição (tratamento 5) e as aves dos tratamentos controle, conforme mostrado na Tabela 4. Estes resultados estão em concordância com FONTANA et al. (1993), os quais concluíram que a restrição alimentar influiu na deposição de gordura em frangos de corte. Conforme estudo de GARCIA et al. (1993), o nível de energia da dieta influenciou $(\mathrm{p}<0,05)$ o rendimento de coxas e gordura abdominal, porém não mostrou efeito sobre o rendimento de carcaça eviscerada, peito e sobrecoxa. Aplicando-se restrição alimentar, que permitiu taxas de crescimento 60 a $75 \%$ do normal, PLAVNIK e HURWITZ (1991) constataram redução significativa $(\mathrm{p}<0,05)$ na gordura abdominal $(\mathrm{g} / \mathrm{kg})$ de frangos machos abatidos aos 56 dias de idade.

\section{Margem bruta}

Aplicou-se a análise bioeconômica, considerando-se o preço do frango ( $\mathrm{kg} /$ ave viva) aos 42 dias e descontando-se o custo das rações nas diferentes fases e o preço do pinto de um dia, conforme mostrado na fórmula da margem bruta. Os resultados obtidos para cada tratamento foram : $\mathrm{T} 1=0,13 ; \mathrm{T} 2=0,10$; $\mathrm{T} 3=0,08 ; \mathrm{T} 4=0,09 ;$ e $\mathrm{T} 5=0,08$.

Os tratamentos em que se aplicaram as restrições não alcançaram a mesma eficiência, apresentando menor margem bruta $(p<0,05)$ que o tratamento controle $(\mathrm{T} 1)$.

\section{Conclusões}

A estratégia nutricional de restrição qualitativa da dieta, na tentativa de reduzir as perdas por mortalidade de origem metabólica e o teor de gordura abdominal na carcaça, foi acompanhada por perdas no desempenho das aves.

\section{Referências Bibliográficas}

ACAR, N., SIZEMORE, F.G., LEACH,G.R. et al. 1995. Growth of broiler chickens in response to feed restriction regimes to reduce ascites. Poult. Sci., 74: 833-843.

ARCE, J., BERGER, M., COELLO, C.L. 1992.Control of ascites syndrome by feed restriction techniques. J. Appl. Poult. Res., 1:1-5.

ENSMINGER, M.E. 1992. Poultry feeding standards, ration formulation andfeeding programs. 3.ed. Danville: Interstate Publishes. p.152 (Animal Agricultural Series).

FONTANA, E.A., WEAVER JR., W.D., WATKINS, B.A. et al.1992. Effect of early restriction on growth, feed conversion and mortality in broiler chickens. Poult. Sci., 71:1296-1305.

FONTANA, E.A., WEAVER, JR., W.D., DENBOW, D.M. et al.1993. Early feed restriction of broilers: effects on abdominal fat pad, liver and gizzard weights, fat deposition and carcass composition. Poult. Sci., 72:243-250.

GARCIA, E.A., MENDES, A.A., SILVA, A.B.P. et al. 1993. Efeito do nível de energia da dieta e do sexo sobre o rendimento de carcaça de frangos de corte. Vet. Zootec., (5):29-37.

GONZALES, E., JUNQUEIRA,O.M., MACARI, M. et al.1994. Influência da idade de produção da matriz na incidência da síndrome da morte súbita em frangos de corte. R. Soc. Bras. Zootec., 23(2):242-248.

GRIFFITHS, L., LEESON, S., SUMMERS, J.D. 1977. Fat deposition in broilers: effect of dietary energy protein balance and early life caloric restriction on productive performance and abdominal fat pad size. Poult. Sci. 56:638-646.

LEESON, S., SUMMERS, J.D. 1988. Some nutritional implications of leg problems with poultry. Br. Vet. J., 144:81-92.

LEESON, S., CASTON, L., SUMMERS, J.D. 1996. Broiler response to energy or energy and protein dilution in the finisher diet. Poult. Sci., 75:522-528.

PALO, P.E., SELL, J.L., PIQUER, F.J. et al. 1995. Effect of early nutrient restriction on broiler chickens.1. Performance and development of the gastrointestinal tract. Poult. Sci. 74:88-101.

PIMENTEL GOMES, F. 1987. Curso de estatística experimental. 12 ed. Piracicaba: ESALQ. 467p.

PLAVNIK, I., HURWITZ, S. 1985. The performance of broiler chicks during and following a severe feed restriction at an early age, Poult. Sci., 64:348-355.

PLAVNIK, I., HURWITZ, S. 1991. Response of broiler chickens and turkey poults to food restriction of varied severity during early life. Br. Poult. Sci., 32(32):343-352.

ROBINSON, F.E., CLASSEN, H.L., HANSON, J.A. et al. 1992. Growth performance, feed efficiency and the incidence of skeletal and metabolic disease in full-fed and feed restricted broiler and roaster chickens. J. Appl. Poult. Res., 1:33-41.

SAS Institute INC. SAS. 1990. User's guide: statistics version 6.04. Cary: SAS Institute Inc. 956p.

SHLOSBER, G.A., BERMANN, E., BENDHEIM,U. et al. 1991 Controlled early feed restriction as a potential means of reducing the incidence of ascites in broilers. Avian Dis., 35(4):681-684.

YU, M.W., ROBINSON, F.E., CLANDININ, L. et al.1990. Growth and body composition of broiler chickens in response to different regimens of feed restriction. Poult. Sci., 69:2074-2081.

ZUBAIR, A.K., LEESON, S. 1994. Effect of varying period of early nutrient restriction on growth compensation and carcass characteristics of male broilers. Poult. Sci., 73:129-136.

Recebido em: 19/06/98

Aceito em: 25/05/99 